University of Nebraska - Lincoln

DigitalCommons@University of Nebraska - Lincoln

Faculty Papers and Publications in Animal

Science

Animal Science Department

8-1-2005

\title{
Genetic parameters for stayability, stayability at calving, and stayability at weaning to specified ages for Hereford cows
}

\author{
G. E. Martinez \\ University of Nebraska-Lincoln \\ R. M. Koch \\ University of Nebraska-Lincoln \\ L. V. Cundiff \\ USDA, ARS, Roman L. Hruska U.S. Meat Animal Research Center \\ K. E. Gregory \\ USDA, ARS, Roman L. Hruska U.S. Meat Animal Research Center \\ Stephen D. Kachman \\ University of Nebraska-Lincoln, steve.kachman@unl.edu \\ See next page for additional authors
}

Follow this and additional works at: https://digitalcommons.unl.edu/animalscifacpub

Part of the Animal Sciences Commons

Martinez, G. E.; Koch, R. M.; Cundiff, L. V.; Gregory, K. E.; Kachman, Stephen D.; and Van Vleck, L. Dale, "Genetic parameters for stayability, stayability at calving, and stayability at weaning to specified ages for Hereford cows" (2005). Faculty Papers and Publications in Animal Science. 210.

https://digitalcommons.unl.edu/animalscifacpub/210

This Article is brought to you for free and open access by the Animal Science Department at DigitalCommons@University of Nebraska - Lincoln. It has been accepted for inclusion in Faculty Papers and Publications in Animal Science by an authorized administrator of DigitalCommons@University of Nebraska - Lincoln. 


\section{Authors}

G. E. Martinez, R. M. Koch, L. V. Cundiff, K. E. Gregory, Stephen D. Kachman, and L. Dale Van Vleck 


\title{
Genetic parameters for stayability, stayability at calving, and stayability at weaning to specified ages for Hereford cows ${ }^{1}$
}

\author{
G. E. Martinez ${ }^{* 2}$, R. M. Koch*, L. V. Cundiff§, K. E. Gregory§, S. D. Kachman $\dagger$, \\ and L. D. Van Vleck $\$ \$^{3}$
}

Departments of *Animal Science and †Statistics, University of Nebraska, Lincoln 68583; and USDA, ARS, Roman L. Hruska U.S. Meat Animal Research Center, §Clay Center, NE 68933 and $\ddagger$ Lincoln, NE 68583-0908

\begin{abstract}
Genetic parameters for stayability to six ages (ST1, .., ST6), for five measures of stayability to calving (SC2, ..., SC6), and for five measures of stayability to weaning (SW2, .., SW6), were estimated using records of 2,019 Hereford cows collected from 1964 to 1979 from a selection experiment with a control line and three lines selected for weaning weight, yearling weight, and an index of yearling weight and muscle score. The model included birth year of the cow as a fixed effect and the cow's sire as a random effect. Analyses were performed with 1) a generalized linear mixed model for binary data using a probit link with a penalized quasi-likelihood function, and 2) with a linear mixed model using REML. Genetic trends were estimated by regressing weighted means of estimated transmitting abilities (ETA) of sires by birth year of their daughters on birth year. Environmental trends were estimated by regressing solutions for year of birth on birth year. Estimates of heritability (SE) for ST were between $0.09(0.08)$ and $0.30(0.14)$ for threshold model and between 0.05 (0.04) and 0.19 (0.09) for linear model. Estimates of heritability from linear model analyses transformed to an underlying normal scale were be-
\end{abstract}

tween 0.09 and 0.35. Estimates of heritability (SE) for SC were between $0.29(0.10)$ and $0.39(0.11)$ and between $0.18(0.09)$ and $0.25(0.08)$ with threshold and linear models. Estimates of heritability transformed to an underlying normal scale were between 0.30 and 0.40 . Estimates of heritability (SE) for SW were between 0.21 $(0.14)$ and $0.47(0.19)$ and between $0.12(0.08)$ and 0.26 (0.12) with threshold and linear models, respectively. Estimates of heritability transformed to an underlying normal scale were between 0.21 and 0.50. Estimates of genetic and environmental trends for all lines were nearly zero for all traits. Correlations between ETA of sires for stayability to specific ages, for stayability to calving, and for stayability to weaning with threshold and linear models ranged from 0.09 to 0.82 , from 0.68 to 0.90 , and from 0.67 to 0.87 , respectively. Selection for stayability would be possible in a breeding program and could be relatively effective as a result of the moderate estimates of heritability, which would allow selection of sires whose daughters are more likely to remain longer in the herd. Selection for weaning and yearling weights resulted in little correlated response for any of the measures of stayability.

Key Words: Beef Cattle, Longevity, Selection

(C2005 American Society of Animal Science. All rights reserved.

J. Anim. Sci. 2005. 83:2033-2042

\section{Introduction}

Selection on predictors of genetic value for stayability represents an opportunity to decrease costs and in-

\footnotetext{
${ }^{1}$ Published as Paper No. 14794, Journal Ser., Nebraska Agric. Res. Div. Univ. of Nebraska, Lincoln 68583-0908.

${ }^{2}$ Current address: Instituto de Producción Animal, Facultad de Agronomia, Universidad Central de Venezuela, Apartado Postal 4579, Maracay 2101, Aragua, Venezuela.

${ }^{3}$ Correspondence: A218 Dept. of Anim. Sci., Univ. of Nebraska, Lincoln (phone: 402-472-6010; fax: 402-472-6362; e-mail: lvanvleck@ unlnotes.unl.edu).

Received October 19, 2004.

Accepted May 28, 2005.
}

crease net income. For a commercial cow-calf producer with a primary goal to produce a live and healthy calf every year, no factor plays a more vital role than the reproductive fitness of cows in the herd. Replacement heifer development requires a large investment of time and resources. A cattle producer, to be economically successful, must keep replacements in the herd long enough to produce enough calves to cover costs of the replacements (Doyle et al., 2000).

Predictions of genetic value for stayability to a specific age, to calving, or to weaning, of beef cows may be used to identify potential parents whose daughters would be most likely to stay in production for a longer time. Reproductive performance is a major component of culling decisions, and stayability is an indicator of 
reproductive performance. Stayability to calving (i.e., whether a cow has a second calf given it had a calf as a $2 \mathrm{yr}$ old) is a measure of the ability to recover and rebreed after first parturition (Snelling et al., 1995). Stayability to weaning (i.e., whether a cow weans a second calf given the cow weaned the first calf) could be an indicator of ability to recover and rebreed after having and weaning a calf. Stayability to relatively old ages also may be an indicator of soundness, as physical impairments can result in culling (Greer et al., 1980).

The objectives of this study were to 1 ) estimate genetic parameters for six measures of stayability to specific ages, five measures of stayability to calving, and five measures of stayability to weaning; and 2) estimate genetic and environmental trends for these stayability traits for a control and three selected lines of Hereford cows.

\section{Materials and Methods}

\section{The Project}

Data were from the Nebraska Agricultural Experiment Station Project 40-002 entitled "Effect of selection for weaning weight, yearling weight, and muscling in beef cattle" in cooperation with the Roman L. Hruska U.S. Meat Animal Research Center, ARS, USDA (USMARC; Koch et al., 1974a,b, 1994). Data used were from animals born from 1964 through 1980.

\section{The Population}

The three selection lines were established in 1960 by randomly allocating 325 cows from 14 Hereford herds to a weaning weight line (WWL), a yearling weight line (YWL), and an index line based on yearling weight and muscle score (IXL). The 42 foundation sires used from 1957 to 1963 were from 11 of the same 14 herds as the cows and from two other herds (Koch et al., 1974a,b, 1994).

The cattle were at Fort Robinson Beef Cattle Research Station, Crawford, NE, until 1971, when they were moved to USMARC, near Clay Center, NE. The projected herd size of 150 breeding females per line was reached by 1964 and maintained until the end of the experiment. A control line (CTL) was introduced in 1971, using 20 representative sons and heifer calves from matings by AI of 225 foundation cows and seven foundation sires (Koch et al., 1974a,b, 1994).

Selection in WWL was based on weight adjusted to $200 \mathrm{~d}$ of age. Selection in YWL was based on weight at $452 \mathrm{~d}$ (approximately $15 \mathrm{mo}$ of age) for bulls and at 550 d (approximately 18 mo of age) for heifers. Selection in IXL was based on an index giving equal emphasis to muscle score and yearling weight, when both were expressed as units of phenotypic standard deviations. Selection of heifers in IXL from birth years of 1960 through 1965 was based on yearling weight alone. Originally, only bulls were evaluated for muscle score, but beginning in the 1966 birth year, heifers also were evaluated for muscle score and also were selected for an index of muscle score and yearling weight until the end of the experiment (Koch et al., 1974a,b, 1994). Selection continued through matings to produce the 1982 calf crop.

Bulls were selected at $2 \mathrm{yr}$ of age. Through 1970, two bulls were chosen for each line from each year of birth and used to sire calves at 3,4 , and 5 yr of age. After 1970, three 2-yr-old bulls were selected each year to be used for $2 \mathrm{yr}$ (i.e., they sired calves when 3 and $4 \mathrm{y}$ of age). Bulls were removed from service early only because of breeding unsoundness. To minimize inbreeding, no more than two sons of a given sire or dam were selected (Koch et al., 1974a,b, 1994). Heifers born in 1964 and later were bred to calve at $2 \mathrm{yr}$ of age. All weaned heifers were exposed to bulls in the breeding pastures. Selection of heifers for the experimental lines was practiced only among those that were pregnant. Through 1970, the best 25 heifers from each line were selected based on the criterion for their line. After 1970, the top 35 heifers were selected. After 1973, essentially all pregnant heifers were kept in the herd and any not pregnant were culled. Cows were removed without regard to progeny performance based on the following criteria (Koch et al., 1974a,b, 1994): not pregnant at weaning time; 2) serious unsoundness (e.g., cancer eye, chronic bloat, broken teeth); 3) failure to wean a live calf for two consecutive years; and 4) old age (older cows were removed if, after evaluation of the first three criteria, too many cows were left). Exceptions for Criteria 1 and 3 were made only when additional cows were needed to maintain the herd size.

For each 60-d breeding season (June through July), sires were assigned randomly to females within each cow age-line. Matings of closely related individuals (e.g., half sibs) were avoided. All lines were maintained as one herd except during the breeding season. Springborn calves were weaned at an average age of approximately $200 \mathrm{~d}$ (Koch et al., 1974a,b; 1994).

Calving rates by averages for 3 -yr intervals, beginning with a 5-yr interval (1964 to 1968), were 0.78, 0.75, $0.78,0.89$, and 0.77 for WWL; 0.80, 0.71, 0.73, 0.82, 0.80 for YWL; and $0.80,0.74,0.75,0.86$, and 0.76 for IXL. Beginning with 1969 to 1971 calving rates were 0.84, 0.88, 0.89, and 0.76 for CTL.

Measurements on cows from the control line were included in the analyses as a basis of comparison with the selection lines.

\section{Analysis of Stayability, Stayability at Calving, and Stayability at Weaning}

Three types of stayability were defined. Stayability to a specific age was defined as whether the cow survived to a specific age, given the opportunity (date of birth) to reach that age by termination of experiment. The six stayability traits were defined as whether a cow survived another year of life, given that the cow 
Table 1. Summary of observations for stayability to different ages in years (e.g., ST1 is a measure of whether a cow survived another year of life given that the cow calved as a 2-yr-old)

\begin{tabular}{lcccr}
\hline \hline Trait & No. & Mean & SD & CV, \% \\
\hline ST1 & 1,868 & 0.87 & 0.36 & 42 \\
ST2 & 1,728 & 0.77 & 0.42 & 55 \\
ST3 & 1,566 & 0.69 & 0.47 & 68 \\
ST4 & 1,394 & 0.58 & 0.49 & 84 \\
ST5 & 1,224 & 0.47 & 0.50 & 106 \\
ST6 & 1,095 & 0.26 & 0.43 & 165 \\
\hline
\end{tabular}

calved (live or dead) as a 2-yr-old and was still in the herd 1 yr later (ST1), another 2 (ST2), another 3 (ST3), another 4 (ST4), another 5 (ST5), and another 6 yr (ST6). Observations were binary, with a 1 indicating that a cow survived from first calving to a specific age and a 0 otherwise. The measures of stayability to the specific ages ( 1 to $6 \mathrm{yr}$ ) were considered different traits. Numbers of observations and frequencies of success for measures of stayability to the specific ages ( 1 to $6 \mathrm{yr}$ ) are presented in Table 1.

Stayability to calving was based on the number of calves born to each cow with a binary observation of 1 indicating a cow had a calf, and 0 indicating failure to have a calf. Five age-specific conditional stayability traits were defined as whether a cow had 2 (SC2), 3 (SC3), 4 (SC4), 5 (SC5), or 6 (SC6) calves, given that the cow birthed a calf as a $2 \mathrm{yr}$ old. Each measure of stayability to calving (SC2 to SC6) was considered to be a different trait. Table 2 shows numbers of observations and frequencies of success for measures of stayability to calving.

Stayability to weaning was based on the number of calves weaned by a cow, with a binary observation of 1 indicating a cow weaned a calf, and 0 indicating failure to wean a calf. Five age-specific conditional stayability traits were defined as whether a cow weaned 2 (SW2), 3 (SW3), 4 (SW4), 5 (SW5), and 6 (SW6) calves given that the cow weaned her first calf. Each specific measure of stayability at weaning (SW2 to SW6) was considered to be a different trait. Table 3 summarizes numbers of observations and frequencies of success for stayability to weaning.

Table 2. Summary of observations for stayability to calving (e.g., SC2 is a measure of whether a cow had two calves given that the cow calved as a 2-yr-old)

\begin{tabular}{lcccc}
\hline \hline Trait & No. & Mean & SD & CV, \% \\
\hline SC2 & 2,019 & 0.66 & 0.48 & 73 \\
SC3 & 1,859 & 0.53 & 0.50 & 94 \\
SC4 & 1,664 & 0.43 & 0.50 & 116 \\
SC5 & 1,478 & 0.35 & 0.48 & 137 \\
SC6 & 1,296 & 0.30 & 0.46 & 153 \\
\hline
\end{tabular}

Table 3. Summary of observations for stayability to weaning (e.g., SW2 is a measure of whether a cow weaned two calves given that the cow weaned a calf as a 2-yr-old) ${ }^{a}$

\begin{tabular}{lrccr}
\hline \hline Trait & No. & Mean & SD & CV, \% \\
\hline SW2 & 1,517 & 0.69 & 0.46 & 67 \\
SW3 & 1,369 & 0.54 & 0.50 & 93 \\
SW4 & 1,230 & 0.42 & 0.49 & 117 \\
SW5 & 1,102 & 0.31 & 0.46 & 148 \\
SW6 & 965 & 0.25 & 0.43 & 172 \\
\hline
\end{tabular}

The specified stayability traits were analyzed using both a generalized linear mixed model for a threshold trait and a linear mixed model. Single-trait threshold analyses were conducted with a generalized linear mixed model for binary data with a probit link. The software package, MATVEC (Wang et al., 2002), based on a penalized quasi-likelihood function (Breslow and Clayton, 1993) as described by Kachman (2001), was used with a single-trait threshold sire model to estimate genetic parameters for stayability. Conditional on the fixed and random effects, stayability traits were assumed to follow a binomial distribution. The linear mixed model predictor used was as follows:

$$
\eta=\mathrm{Xb}+\mathrm{Zs}
$$

where $\eta$ is the vector of linear predictors, which is related to predictions on the observational scale through the inverse link function; $b$ is a $p \times 1$ vector of fixed (year) effects; $\mathrm{s}$ is a $\mathrm{q} \times 1$ vector of random sire transmitting abilities, and $\mathrm{X}, \mathrm{Z}$ are known incidence matrices relating the observations in $\mathrm{y}$, the $\mathrm{n} \times 1$ vector of observations, or its conditional expectation, $\mathrm{E}\left[\mathrm{y}_{\mathrm{i}} \mid \eta_{\mathrm{i}}\right]=\mathrm{h}\left(\eta_{\mathrm{i}}\right)=$ $\mathrm{p}_{\mathrm{i}}$, to fixed and random effects respectively. The residual variance on the underlying scale is assumed to be 1 .

The link function was the probit function: $\eta=\Phi^{-1}\left(\mathrm{p}_{\mathrm{i}}\right)$, with inverse link $\mathrm{p}_{\mathrm{i}}=\Phi(\eta)=\int_{-\infty}^{\eta} \frac{1}{\sqrt{2 \pi}} \mathrm{e}^{\frac{-\mathrm{x}^{2}}{2}} \mathrm{dx}$, where $\Phi$ is the cumulative normal density function, and $\mathrm{p}_{\mathrm{i}}$ denotes the probability of survival (success) for cow $\mathbf{i}$. The Bernoulli distribution for a defined stayability trait for a cow, with $\mathrm{y}_{\mathrm{i}}=1$ denoting success and $\mathrm{y}_{\mathrm{i}}=0$ denoting failure, is the probability $\left(y_{i} \mid p_{i}\right)=\left(p_{i}\right)^{y_{i}}\left(1-p_{i}\right)^{1-y_{i}}$.

The estimating equations for the fixed and random effects are as follows:

$$
\left[\begin{array}{cc}
\mathrm{X}^{\prime} \mathrm{H}^{\prime} \mathrm{R}^{-1} \mathrm{HX} & \mathrm{X}^{\prime} \mathrm{H}^{\prime} \mathrm{R}^{-1} \mathrm{HZ} \\
\mathrm{Z}^{\prime} \mathrm{H}^{\prime} \mathrm{R}^{-1} \mathrm{HX} & \mathrm{Z}^{\prime} \mathrm{H}^{\prime} \mathrm{R}^{-1} \mathrm{HZ}+\mathrm{G}^{-1}
\end{array}\right]\left[\begin{array}{c}
\hat{b} \\
\hat{\mathrm{s}}
\end{array}\right]=\left[\begin{array}{l}
\mathrm{X}^{\prime} \mathrm{H}^{\prime} \mathrm{R}^{-1}\left(\mathrm{y}^{*}\right) \\
\mathrm{Z}^{\prime} \mathrm{H}^{\prime} \mathrm{R}^{-1}\left(\mathrm{y}^{*}\right)
\end{array}\right]
$$

where $\mathrm{H}=\operatorname{Diag}\left(H_{i}=\frac{\partial p_{i}}{\partial \eta_{i}}\right)=\operatorname{Diag}\left(\frac{1}{\sqrt{2 \pi}} e^{\frac{-\eta_{\mathrm{i}}^{2}}{2}}\right) ; \quad R=$ $\operatorname{Diag}\left(\operatorname{var}\left(y_{i} \mid \eta_{i}\right)\right)=\operatorname{Diag}\left(p_{i}\left(1-p_{i}\right)\right) ; y_{i}^{*}=y_{i}-\phi\left(\eta_{i}\right)+H_{i} \eta_{i}$, and $\mathrm{G}=\mathrm{A} \sigma_{\mathrm{s}}^{2}$, with the estimate of heritability with the 
threshold model obtained as $\hat{\mathrm{h}}_{\mathrm{t}}^{2}=\frac{4 \hat{\sigma}_{\mathrm{s}}^{2}}{\left(1+\hat{\sigma}_{\mathrm{s}}^{2}\right)}$, with $\hat{\sigma}_{\mathrm{s}}^{2}$ the estimate of variance of sire transmitting abilities.

The 1 in the denominator is because one way to look at the threshold model is that there is an underlying random variable, which is equal to $\eta+\mathrm{e}$ with e distributed $\mathrm{N}(0,1)$, so that the 1 in the denominator is the variance of $\mathrm{e}$.

Single-trait linear mixed models also were used to estimate variance components for all measures of stayability traits without transformation of the records. For all traits, the model included year born as a fixed factor and sire transmitting ability as a random factor.

Analyses for single traits for the linear model were based on the model:

$$
\mathrm{y}=\mathrm{Xb}+\mathrm{Zs}+\mathrm{e}
$$

where $y$ is a $n \times 1$ vector of observations; $b$ is a $p \times 1$ vector of fixed (year) effects; $s$ is a $q \times 1$ vector of random sire transmitting abilities; e is $\mathrm{n} \times 1$ vector of random residual effects; and $\mathrm{X}, \mathrm{Z}$ are known incidence matrices relating the observations to fixed and random effects, respectively.

The first and second moments of the model are assumed to be:

$$
\mathrm{E}[\mathrm{y}]=\mathrm{Xb} \text {, and } \operatorname{Var}\left[\begin{array}{l}
\mathrm{s} \\
\mathrm{e}
\end{array}\right]=\left[\begin{array}{cc}
\mathrm{A} \sigma_{\mathrm{s}}^{2} & 0 \\
0 & \mathrm{I} \sigma_{\mathrm{e}}^{2}
\end{array}\right]
$$

where A is Wright's numerator relationship matrix among sires; $\sigma_{\mathrm{s}}^{2}$ in the variance of transmitting ability; $\sigma_{\mathrm{e}}^{2}$ in the residual variance; and I is an identity matrix with order the number of records.

The estimating equations for the fixed and random effects are as follows:

$$
\left[\begin{array}{cc}
X^{\prime} R^{-1} X & X^{\prime} R^{-1} Z \\
Z^{\prime} R^{-1} X & Z^{\prime} R^{-1} Z+G^{-1}
\end{array}\right]\left[\begin{array}{l}
\hat{b} \\
\hat{s}
\end{array}\right]=\left[\begin{array}{c}
X^{\prime} R^{-1} y \\
Z^{\prime} R^{-1} y
\end{array}\right]
$$

where $\mathrm{G}=\mathrm{A} \sigma_{\mathrm{s}}^{2}$, and $\mathrm{R}=\mathrm{I} \sigma_{\mathrm{e}}^{2}$.

Estimates of variance components and, at convergence, solutions for the fixed and random effects were obtained with MATVEC (Wang et al., 2002) with restricted maximum likelihood. Estimates of heritability on the observed binomial scale were obtained using the following equation:

$$
\hat{\mathrm{h}}_{1}^{2}=\frac{4 \hat{\sigma}_{\mathrm{s}}^{2}}{\left(\hat{\sigma}_{\mathrm{s}}^{2}+\hat{\sigma}_{\mathrm{e}}^{2}\right)}
$$

Estimates of heritability from analyses of binomial observations with the linear model were transformed to an underlying normal scale using the formula described by Robertson and Lerner (1949) as follows:

$$
\mathrm{h}_{\mathrm{u}}^{2}=\frac{\mathrm{h}_{1}^{2} \mathrm{p}(1-\mathrm{p})}{\mathrm{z}^{2}}
$$

where $\mathrm{h}_{\mathrm{u}}^{2}$ is the estimate of heritability on the underlying normal scale; $h_{1}^{2}$ is the estimate of heritability from the linear model with binomial observations; $p$ is the fraction of cows with observations of 1 ; and $\mathrm{z}$ is the height of the ordinate at the truncation point for an area of $p$ under the normal curve.

The standard errors for estimates of heritability were calculated using the Delta method and the information matrix at convergence from estimating the variance components (Searle, 1992).

Genetic changes were estimated by regressing means of estimated transmitting abilities (ETA) of sires on the observed scale by year of birth of their daughters on birth year (Blair and Pollak, 1984). Environmental trends were estimated by regressing solutions for year of birth of the daughters on birth year. The regressions assume response is linear over time and allow differences between CTL and selected lines to be tested by comparing regression coefficients with $t$-tests.

Simple correlations among ETA of sires within each definition of stayability were calculated as an indication of the relationship between different measures of stayability within each definition of stayability. Simple correlations among ETA for ST5, SC5, and SW5 also were calculated as an indication of the relationships across definitions of stayability.

These correlations among ETA are not genetic correlations because the correlations do not account for some environmental variance in the denominator terms. Because observations of stayability to different ages are not independent, residual effects for ETA for stayability to one age also would be associated with ETA for stayability to other ages.

\section{Results and Discussion}

\section{Estimates of Genetic Parameters}

Estimates of heritability and standard errors with threshold and linear models for stayability at specific ages are summarized in Table 4. In general, estimates of heritability ranged from low $(0.09 \pm 0.08)$ for ST3 to moderate $(0.30 \pm 0.14)$ for ST6, with the threshold model.

Estimates of heritability using a linear model with binomial observations followed the same trend as those with a threshold model and ranged from $0.05 \pm 0.04$ for ST3 to $0.15 \pm 0.07$ for ST6. Estimates of heritability transformed to an underlying normal scale were in close agreement with those from the threshold model, ranging from low (0.09) for ST3 to moderate (0.35) for ST6.

Estimates of heritability with the linear model are in agreement with those reported in the literature. Previous studies in dairy cattle (Hudson and Van Vleck, 1981; Van Doormaal et al., 1985; DeLorenzo and Ever- 
Table 4. Estimates of heritability and standard errors for stayability to specific ages in years (e.g., ST1 is a measure of whether a cow survived another year of life given that the cow calved as a 2-yr-old) ${ }^{\mathrm{a}}$

\begin{tabular}{|c|c|c|c|c|c|c|c|c|}
\hline \multirow[b]{2}{*}{ Trait } & \multirow[b]{2}{*}{ Mean } & \multicolumn{3}{|c|}{ Threshold model } & \multicolumn{4}{|c|}{ Linear model } \\
\hline & & $\sigma_{\mathrm{s}}^{2}$ & $\mathrm{~h}_{\mathrm{t}}^{2}$ & se & $\sigma_{\mathrm{s}}^{2}$ & $\mathrm{~h}_{1}^{2}$ & se & $\mathrm{h}_{\mathrm{u}}^{2}$ \\
\hline ST1 & 0.87 & 0.0608 & 0.23 & 0.12 & 0.0024 & 0.09 & 0.06 & 0.24 \\
\hline ST2 & 0.77 & 0.0421 & 0.16 & 0.10 & 0.0030 & 0.08 & 0.05 & 0.16 \\
\hline ST3 & 0.69 & 0.0229 & 0.09 & 0.08 & 0.0022 & 0.05 & 0.04 & 0.09 \\
\hline ST4 & 0.58 & 0.0653 & 0.25 & 0.12 & 0.0068 & 0.15 & 0.07 & 0.24 \\
\hline ST5 & 0.47 & 0.0435 & 0.17 & 0.11 & 0.0054 & 0.11 & 0.07 & 0.17 \\
\hline ST6 & 0.26 & 0.0813 & 0.30 & 0.14 & 0.0095 & 0.19 & 0.09 & 0.35 \\
\hline
\end{tabular}

${ }^{\mathrm{a}} \sigma_{\mathrm{s}}^{2}=$ sire variance; $\mathrm{h}_{\mathrm{t}}^{2}=$ heritability with threshold model; se = standard error; $\mathrm{h}_{1}^{2}=$ heritability with linear model; and $\mathrm{h}_{\mathrm{u}}^{2}=$ heritability from linear model transformed to underlying normal scale.

ett, 1986) have reported estimates of heritability of less than 0.10 for stayability to different ages on the observed binomial scale with use of linear models.

Hudson and Van Vleck (1981) found estimates of heritability with records measured on the binomial scale that ranged from 0.02 to 0.05 for stayability to 36 and to 84 mo of age. Van Doormaal et al. (1985) reported estimates of heritability with records measured on the binomial scale of $0.05,0.04,0.05,0.06$ for stayability to $41,54,66$, and $78 \mathrm{mo}$ of age, respectively. DeLorenzo and Everett (1986), using a logistic regression model, obtained estimates of heritability of 0.28 and 0.26 for stayability at 41 and 54 mo of age on the underlying normal scale, corresponding to 0.12 and 0.15 on the observed (binomial) scale. Those estimates for dairy cattle are in close agreement with estimates found in the present research. Bijma and Jansen (1996) reported estimates of heritability on the observed binomial scale of $0.05,0.08$, and 0.11 for stayability to 36,54 , and 85 mo of age, respectively. Vollema and Groen (1996) reported estimates of heritability for stayability at 36 , 48,60 , and 72 mo of age ranging from 0.01 to 0.12 estimated from binomial data using a linear model, and from 0.02 to 0.19 when transformed to an underlying normal scale.

Vega (1999), using a sire model with measurements from an experimental herd of beef cattle, reported estimates of heritability with a threshold model of 0.00 ,
$0.08,0.02,0.22,0.25,0.28$, and 0.00 for stayability at $2,3,4,5,6,7$, and $8 \mathrm{yr}$ of age. The corresponding estimates of heritability with the linear model using binary observations were $0.01,0.03,0.03,0.14,0.14$, 0.15 , and 0.00 for stayability at $2,3,4,5,6,7$, and 8 $\mathrm{yr}$ of age; when transformed to the underlying normal scale, estimates were $0.06,0.10,0.08,0.34,0.32,0.32$, and 0.00 , some of which were greater than estimates with the threshold model.

Estimates of heritability and standard errors with threshold and linear models for stayability to calving are summarized in Table 5. In general, estimates of heritability were moderate, ranging from $0.29 \pm 0.10$ for SC4 to $0.39 \pm 0.11$ for SC2 with a threshold model. Estimates of heritability with a linear model (measurements on binomial scale) were less than those with the threshold model, ranging from $0.18 \pm 0.09$ for SC4 to $0.25 \pm 0.07$ for SC2, but when transformed to an underlying normal scale, they were in close agreement with those with the threshold model and ranged from 0.30 for SC4 to 0.40 for SC2.

Snelling et al. (1995), with an equivalent definition of stayability at calving and using an animal model, reported estimates of heritability on the underlying normal scale ranging from 0.09 to 0.20 and 0.02 to 0.12 for two herds. When transformed to the observed binary scale, estimates of heritability ranged from 0.04 to 0.07 and 0.01 to 0.09 for the two herds. Analyses with a sire

Table 5. Estimates of heritability and standard errors for stayability to calving (e.g., SC2 is a measure of whether a cow had two calves given that the cow calved as a 2-yr-old) ${ }^{a}$

\begin{tabular}{|c|c|c|c|c|c|c|c|c|}
\hline \multirow[b]{2}{*}{ Trait } & \multirow[b]{2}{*}{ Mean } & \multicolumn{3}{|c|}{ Threshold model } & \multicolumn{4}{|c|}{ Linear model } \\
\hline & & $\sigma_{\mathrm{s}}^{2}$ & $\mathrm{~h}_{\mathrm{t}}^{2}$ & se & $\sigma_{\mathrm{s}}^{2}$ & $\mathrm{~h}_{1}^{2}$ & se & $\mathrm{h}_{\mathrm{u}}^{2}$ \\
\hline $\mathrm{SC} 2$ & 0.66 & 0.1072 & 0.39 & 0.11 & 0.0125 & 0.24 & 0.07 & 0.40 \\
\hline SC3 & 0.53 & 0.1042 & 0.38 & 0.11 & 0.0142 & 0.25 & 0.08 & 0.39 \\
\hline $\mathrm{SC} 4$ & 0.43 & 0.0766 & 0.29 & 0.10 & 0.0106 & 0.19 & 0.07 & 0.30 \\
\hline SC5 & 0.35 & 0.0969 & 0.35 & 0.13 & 0.0094 & 0.19 & 0.08 & 0.31 \\
\hline SC6 & 0.30 & 0.1062 & 0.38 & 0.15 & 0.0081 & 0.18 & 0.09 & 0.30 \\
\hline
\end{tabular}

${ }^{\mathrm{a}} \sigma_{\mathrm{s}}^{2}=$ sire variance; $\mathrm{h}_{\mathrm{t}}^{2}=$ heritability with threshold model; se = standard error; $\mathrm{h}_{1}^{2}=$ heritability with linear model; and $\mathrm{h}_{\mathrm{u}}^{2}=$ heritability from linear model transformed to underlying normal scale. 
Table 6. Estimates of heritability and standard errors for stayability to weaning (e.g., SW2 is a measure of whether a cow weaned two calves given that the cow weaned a calf as a 2 -yr-old) ${ }^{\mathrm{a}}$

\begin{tabular}{|c|c|c|c|c|c|c|c|c|}
\hline \multirow[b]{2}{*}{ Trait } & \multirow[b]{2}{*}{ Mean } & \multicolumn{3}{|c|}{ Threshold model } & \multicolumn{4}{|c|}{ Linear model } \\
\hline & & $\sigma_{\mathrm{s}}^{2}$ & $\mathrm{~h}_{\mathrm{t}}^{2}$ & se & $\sigma_{\mathrm{s}}^{2}$ & $\mathrm{~h}_{1}^{2}$ & se & $\mathrm{h}_{\mathrm{u}}^{2}$ \\
\hline SW2 & 0.69 & 0.0833 & 0.31 & 0.12 & 0.0095 & 0.18 & 0.08 & 0.31 \\
\hline SW3 & 0.54 & 0.0639 & 0.24 & 0.11 & 0.0090 & 0.15 & 0.08 & 0.24 \\
\hline SW4 & 0.42 & 0.0754 & 0.28 & 0.13 & 0.0115 & 0.20 & 0.09 & 0.32 \\
\hline SW5 & 0.31 & 0.0548 & 0.21 & 0.14 & 0.0061 & 0.12 & 0.08 & 0.21 \\
\hline SW6 & 0.25 & 0.1314 & 0.47 & 0.19 & 0.0120 & 0.26 & 0.12 & 0.50 \\
\hline
\end{tabular}

${ }^{\mathrm{a}} \sigma_{\mathrm{s}}^{2}=$ sire variance; $\mathrm{h}_{\mathrm{t}}^{2}=$ heritability with threshold model; se = standard error; $\mathrm{h}_{1}^{2}=$ heritability with linear model; and $\mathrm{h}_{\mathrm{u}}^{2}=$ heritability from linear model transformed to underlying normal scale.

model resulted in estimates of heritability ranging from 0.08 to 0.12 in one herd and from 0.07 to 0.71 in the second herd. These estimates were 4 to 10 times greater than estimates with an animal model for the same trait. The authors suggested that these results may have been due to lack of sire information in one of the herds, where $60 \%$ of the sires of dams were unknown and known sires were confounded with years.

Vega (1999), using a sire model with measurements from an experimental herd of beef cattle, reported estimates of heritability with a threshold model of 0.27 , $0.22,0.25,0.13$, and 0.10 for SC2, SC3, SC4, SC5, and SC6, respectively. Estimates of heritability with a linear model (binary observations) were $0.18,0.14,0.17$, 0.08 , and 0.05 for SC2, SC3, SC4, SC5, and SC6, and when transformed to an underlying normal scale, estimates were $0.80,0.43,0.43,0.16$, and 0.08 .

Estimates of heritability and standard errors with threshold and linear models for stayability at weaning are summarized in Table 6. In general, estimates of heritability were moderate, ranging from $0.21 \pm 0.14$ for SW5 to $0.47 \pm 0.19$ for SW6 with a threshold model. Estimates of heritability with linear model (binomial scale) are less that those with threshold model, ranging from $0.12 \pm 0.08$ to $0.26 \pm 0.12$. Estimates of heritability transformed to an underlying scale are in close agreement with those with threshold model.

Vega (1999), with an equivalent definition of stayability at weaning and using a sire model with measurements from an experimental herd of beef cattle, reported estimates of heritability with a threshold model of $0.21,0.28,0.11,0.12$, and 0.12 for SW2, SW3, SW4, SW5, and SW6. Estimates of heritability with a linear model (binary observations) were $0.12,0.19,0.07,0.06$, and 0.07 for SW2, SW3, SW4, SW5, and SW6 and when transformed to an underlying normal scale were 0.48 , $0.53,0.15,0.11$, and 0.11 .

\section{Estimates of Genetic and Environmental Changes}

Tables 7 and 8 summarize estimates of genetic and environmental change for stayability to specific ages, based on ETA with linear and threshold models, respectively. In general, estimates of genetic and environmen- tal trends were in close agreement for linear (Table 7) and threshold (Table 8) models. Estimates of genetic trends did not follow a pattern. All four lines had negative and positive estimates of annual change for different definitions of stayability; however, all estimates of annual genetic change were close to zero. The biggest difference between a selected line (YWL) and CTL was for ST4, with differences in favor of CTL of 0.0050 and $0.0046 / \mathrm{yr}$, which are with the observed binomial scale of 0 to 1 from linear and threshold models, respectively; however, differences for annual change in stayability between the selection lines (WWL, YWL, and IXL) and the control line (CTL) were not significantly different from zero $(P>0.05)$. Estimates of environmental trend were significantly negative for all measures of stayability with the change increasing with age. The negative environmental trends (year solutions) may be an artifact of having more cows than spaces in the herd in later years or may be due to management, resulting in more cows leaving the herd. Unfortunately, other estimates of genetic and environmental changes for stayability at specific ages are not available for comparison.

Tables 9 and 10 summarize the genetic and environmental changes for stayability to calving based on ETA with linear and threshold models, respectively. In general, estimates of the genetic and environmental trends were in close agreement for linear (Table 9) and threshold (Table 10) models. Estimates of genetic trends were negative for all three selected lines and slightly positive for the control line, but all estimates of annual change were nearly zero. The greatest differences between a selected line (YWL) and CTL were for SC5, with differences of 0.0044 and $0.0049 / y r$ with linear and threshold models, respectively. No significant differences were detected between selection lines and the control line $(P>0.05)$ for any measure of stayability to calving. Estimates of annual environmental changes were significantly negative for all measure of stayability to calving. Estimates of genetic change were similar to estimates reported by Snelling et al. (1995), and estimates of environmental changes are in agreement with estimates by those authors. 
Table 7. Estimates by selection line of annual genetic and environmental changes for different measures of stayability with linear models (e.g., ST1 is a measure of whether a cow survived another year of life given that the cow calved as a 2-yr-old) ${ }^{a}$

\begin{tabular}{lrrrrr}
\hline \hline & \multicolumn{4}{c}{ Genetic } \\
\cline { 2 - 5 } Trait & \multicolumn{1}{c}{ WWL } & \multicolumn{1}{c}{ YWL } & \multicolumn{1}{c}{ IXL } & \multicolumn{1}{c}{ CTL } & Environmental \\
\hline ST1 & $-0.0009 \pm 0.0002$ & $0.0007 \pm 0.0003$ & $0.0002 \pm 0.0002$ & $-0.0003 \pm 0.0005$ & $-0.0223 \pm 0.0060$ \\
ST2 & $-0.0003 \pm 0.0002$ & $0.0000 \pm 0.0004$ & $0.0003 \pm 0.0003$ & $0.0004 \pm 0.0003$ & $-0.0356 \pm 0.0054$ \\
ST3 & $-0.0000 \pm 0.0003$ & $-0.0006 \pm 0.0003$ & $0.0003 \pm 0.0003$ & $-0.0002 \pm 0.0004$ & $-0.0476 \pm 0.0056$ \\
ST4 & $-0.0005 \pm 0.0003$ & $-0.0037 \pm 0.0010$ & $0.0012 \pm 0.0008$ & $0.0013 \pm 0.0010$ & $-0.0622 \pm 0.0055$ \\
ST5 & $-0.0002 \pm 0.0003$ & $-0.0013 \pm 0.0004$ & $-0.0002 \pm 0.0005$ & $0.0015 \pm 0.0011$ & $-0.0662 \pm 0.0051$ \\
ST6 & $0.0001 \pm 0.0007$ & $-0.0022 \pm 0.0005$ & $-0.0013 \pm 0.0009$ & $0.0024 \pm 0.0013$ & $-0.0722 \pm 0.0084$ \\
\hline
\end{tabular}

${ }^{a} \mathrm{WWL}=$ Weaning weight line; YWL = Yearling weight line; IXL = Index line; and CTL = Control line. Differences in annual genetic change between selection lines and the Control line were not significant.

Table 8. Estimates by selection line of annual genetic and environmental changes for different measures of stayability with threshold models (e.g., ST1 is a measure of whether a cow survived another year of life given that the cow calved as a 2-yr-old) ${ }^{\mathrm{a}}$

\begin{tabular}{lrrrrr}
\hline \hline & \multicolumn{4}{c}{ Genetic } & \\
\cline { 2 - 5 } Trait & \multicolumn{1}{c}{ WWL } & \multicolumn{1}{c}{ YWL } & \multicolumn{1}{c}{ IXL } & \multicolumn{1}{c}{ CTL } & Environmental \\
\hline ST1 & $-0.0009 \pm 0.0003$ & $0.0009 \pm 0.0003$ & $0.0002 \pm 0.0002$ & $-0.0001 \pm 0.0007$ & $-0.0223 \pm 0.0060$ \\
ST2 & $-0.0003 \pm 0.0002$ & $0.0000 \pm 0.0004$ & $0.0004 \pm 0.0003$ & $0.0004 \pm 0.0003$ & $-0.0356 \pm 0.0054$ \\
ST3 & $-0.0000 \pm 0.0002$ & $-0.0006 \pm 0.0002$ & $0.0003 \pm 0.0002$ & $-0.0002 \pm 0.0004$ & $-0.0478 \pm 0.0057$ \\
ST4 & $-0.0004 \pm 0.0002$ & $-0.0034 \pm 0.0008$ & $0.0011 \pm 0.0006$ & $0.0012 \pm 0.0005$ & $-0.0631 \pm 0.0056$ \\
ST5 & $-0.0001 \pm 0.0003$ & $-0.0011 \pm 0.0004$ & $-0.0002 \pm 0.0004$ & $0.0013 \pm 0.0010$ & $-0.0670 \pm 0.0053$ \\
ST6 & $0.0002 \pm 0.0005$ & $-0.0016 \pm 0.0004$ & $-0.0009 \pm 0.0007$ & $0.0020 \pm 0.0011$ & $-0.0730 \pm 0.0085$ \\
\hline
\end{tabular}

${ }^{a}$ WWL = Weaning weight line; YWL = Yearling weight line; IXL = Index line; and CTL = Control line. Differences in annual genetic change between selection lines and the control line were not significant.

Table 9. Estimates by selection line of annual genetic and environmental changes for stayability to calving with linear models (e.g., SC2 is a measure of whether a cow had two calves given that the cow calved as a 2 -yr-old $)^{\text {a }}$

\begin{tabular}{lccccc}
\hline \hline & \multicolumn{4}{c}{ Genetic } & \\
\cline { 2 - 5 } Trait & WWL & YWL & IXL & CTL & Environmental \\
\hline SC2 & $-0.0017 \pm 0.0005$ & $-0.0006 \pm 0.0007$ & $-0.0006 \pm 0.0005$ & $0.0009 \pm 0.0017$ & $-0.0175 \pm 0.0073$ \\
SC3 & $-0.0012 \pm 0.0008$ & $-0.0015 \pm 0.0009$ & $-0.0019 \pm 0.0005$ & $0.0021 \pm 0.0019$ & $-0.0259 \pm 0.0073$ \\
SC4 & $-0.0010 \pm 0.0007$ & $-0.0025 \pm 0.0010$ & $-0.0010 \pm 0.0005$ & $0.0007 \pm 0.0015$ & $-0.0322 \pm 0.0073$ \\
SC5 & $-0.0014 \pm 0.0007$ & $-0.0021 \pm 0.0009$ & $-0.0008 \pm 0.0005$ & $0.0021 \pm 0.0017$ & $-0.0431 \pm 0.0066$ \\
SC6 & $-0.0012 \pm 0.0009$ & $-0.0013 \pm 0.0007$ & $-0.0015 \pm 0.0008$ & $0.0023 \pm 0.0028$ & $-0.0461 \pm 0.0071$ \\
\hline
\end{tabular}

${ }^{\mathrm{a} W W L}=$ Weaning weight line; YWL = Yearling weight line; IXL = Index line; and CTL = Control line. Differences in annual genetic change between selection lines and the control line were not significant.

Table 10. Estimates by selection line of annual genetic and environmental changes for stayability to calving with threshold models (e.g., SC2 is a measure of whether a cow had two calves given that the cow calved as a 2-yr-old $)^{\text {a }}$

\begin{tabular}{|c|c|c|c|c|c|}
\hline \multirow[b]{2}{*}{ Trait } & \multicolumn{4}{|c|}{ Genetic } & \multirow[b]{2}{*}{ Environmental } \\
\hline & WWL & YWL & IXL & CTL & \\
\hline $\mathrm{SC} 2$ & $-0.0017 \pm 0.0006$ & $-0.0007 \pm 0.0007$ & $-0.0009 \pm 0.0006$ & $0.0010 \pm 0.0019$ & $-0.0172 \pm 0.0074$ \\
\hline SC3 & $-0.0010 \pm 0.0008$ & $-0.0013 \pm 0.0008$ & $-0.0018 \pm 0.0005$ & $0.0021 \pm 0.0019$ & $-0.0262 \pm 0.0074$ \\
\hline SC4 & $-0.0008 \pm 0.0006$ & $-0.0022 \pm 0.0010$ & $-0.0008 \pm 0.0005$ & $0.0007 \pm 0.0015$ & $-0.0327 \pm 0.0074$ \\
\hline SC5 & $-0.0015 \pm 0.0007$ & $-0.0022 \pm 0.0010$ & $-0.0005 \pm 0.0005$ & $0.0027 \pm 0.0019$ & $-0.0442 \pm 0.0067$ \\
\hline SC6 & $-0.0013 \pm 0.0009$ & $-0.0014 \pm 0.0007$ & $-0.0014 \pm 0.0008$ & $0.0022 \pm 0.0039$ & $-0.0476 \pm 0.0072$ \\
\hline
\end{tabular}

${ }^{\mathrm{a} W W L}=$ Weaning weight line; YWL = Yearling weight line; IXL = Index line; and CTL = Control line. Differences in annual genetic change between selection lines and the control line were not significant. 
Table 11. Estimates of annual genetic and environmental changes by selection line for stayability to weaning with linear models (e.g., SW2 is measure of whether a cow weaned two calves given that the cow weaned a calf as a 2-yr-old $)^{a}$

\begin{tabular}{crcccc}
\hline \hline & \multicolumn{4}{c}{ Genetic } & \\
\cline { 2 - 5 } Trait & WWL & YWL & IXL & CTL & Environmental \\
\hline SW2 & $-0.0003 \pm 0.0004$ & $-0.0007 \pm 0.0005$ & $-0.0007 \pm 0.0003$ & $0.0008 \pm 0.0010$ & $-0.0106 \pm 0.0061$ \\
SW3 & $0.0003 \pm 0.0005$ & $-0.0011 \pm 0.0006$ & $-0.0016 \pm 0.0006$ & $0.0015 \pm 0.0010$ & $-0.0139 \pm 0.0078$ \\
SW4 & $0.0005 \pm 0.0006$ & $-0.0019 \pm 0.0008$ & $-0.0015 \pm 0.0005$ & $0.0021 \pm 0.0016$ & $-0.0194 \pm 0.0078$ \\
SW5 & $-0.0005 \pm 0.0003$ & $-0.0014 \pm 0.0007$ & $-0.0001 \pm 0.0003$ & $0.0011 \pm 0.0012$ & $-0.0294 \pm 0.0055$ \\
SW6 & $-0.0003 \pm 0.0006$ & $-0.0021 \pm 0.0010$ & $-0.0026 \pm 0.0011$ & $0.0070 \pm 0.0043$ & $-0.0276 \pm 0.0059$ \\
\hline
\end{tabular}

${ }^{a} \mathrm{WWL}=$ Weaning weight line; YWL = Yearling weight line; IXL = Index line; and CTL = Control line. Differences in annual genetic change between selection lines and the control line were not significant.

Estimates of genetic and environmental changes for stayability to weaning with linear and threshold models are summarized in Tables 11 and 12, respectively. In general, estimates of the annual genetic and environmental changes were in close agreement for linear (Table 11) and threshold (Table 12) models. Estimates of genetic trends were negative for all three selected lines and slightly positive for the control line, but all estimates were not significantly different from zero. The greatest differences between a selected line (IXL) and CTL were for SW6 with differences of 0.0096 and $0.0098 / y r$, with linear and threshold models, respectively. No significant differences were detected between selection lines and the control line $(P>0.05)$ for any measure of stayability at weaning. Estimates of environmental trends were negative for all measures of stayability at weaning and significantly different from zero for measures at older ages. Previous estimates of genetic and environmental changes for stayability at weaning were not found for comparison, except for those by Snelling et al. (1995).

The lack of genetic change for stayability to specified ages, stayability to calving, and stayability to weaning is not surprising, as no direct selection was applied for these traits in any of the lines, which suggests near zero genetic correlations between stayability and traits on which selection was practiced (WWL, YWL, IXL).

\section{Correlations Among Estimated Transmitting Abilities}

Table 13 summarizes correlations among ETA of sires for stayability to specific ages with linear and threshold models. Estimates of correlations were similar with both models and ranged from low to high. Estimates of correlations ranged from 0.11 to 0.09 between ST1 and ST5 and 0.82 between ST2 and ST3, for both linear and threshold models, respectively. The pattern was for correlations to be greatest between adjacent ages.

Correlations among ETA for measures of stayability at calving with linear models ranged from 0.68 between SC2 and SC6 to 0.90 between SC3 and SC4. Similar results were found with threshold models, with correlations ranging from 0.68 between SC2 and SC5 to 0.90 between SC3 and SC4. Estimates of correlations are similar with both models and are generally large as summarized in Table 14.

Table 15 summarizes correlations among ETA for measures of stayability to weaning with linear and threshold models. Estimates of correlations were the same with both models and were generally large. Estimates of correlations ranged from 0.67 between SW2 and SW5 to 0.87 between SW3 and SW4, for both linear and threshold models and were generally similar to those for stayability to calving. In general, correlations

Table 12. Estimates of annual genetic and environmental changes by selection line for stayability to weaning with threshold models (e.g., SW2 is measure of whether a cow weaned two calves given that the cow weaned a calf as a 2-yr-old) ${ }^{\mathrm{a}}$

\begin{tabular}{|c|c|c|c|c|c|}
\hline \multirow[b]{2}{*}{ Trait } & \multicolumn{4}{|c|}{ Genetic } & \multirow[b]{2}{*}{ Environmental } \\
\hline & WWL & YWL & IXL & CTL & \\
\hline SW2 & $-0.0002 \pm 0.0005$ & $-0.0007 \pm 0.0005$ & $-0.0007 \pm 0.0005$ & $0.0009 \pm 0.0011$ & $-0.0106 \pm 0.0062$ \\
\hline SW3 & $0.0004 \pm 0.0005$ & $-0.0010 \pm 0.0005$ & $-0.0015 \pm 0.0005$ & $0.0016 \pm 0.0009$ & $-0.0140 \pm 0.0080$ \\
\hline SW4 & $0.0004 \pm 0.0005$ & $-0.0016 \pm 0.0008$ & $-0.0012 \pm 0.0005$ & $0.0017 \pm 0.0013$ & $-0.0197 \pm 0.0080$ \\
\hline SW5 & $-0.0005 \pm 0.0003$ & $-0.0014 \pm 0.0007$ & $0.0000 \pm 0.0003$ & $0.0011 \pm 0.0010$ & $-0.0298 \pm 0.0055$ \\
\hline SW6 & $-0.0004 \pm 0.0005$ & $-0.0020 \pm 0.0010$ & $-0.0023 \pm 0.0011$ & $0.0075 \pm 0.0046$ & $-0.0288 \pm 0.0060$ \\
\hline
\end{tabular}

${ }^{a}$ WWL = Weaning weight line; YWL = Yearling weight line; IXL = Index line; and CTL = Control line. Differences in annual genetic change between selection lines and the control line were not significant. 
Table 13. Correlations among estimated transmitting abilities of sires for stayability to specific ages (e.g., ST1 is a measure of whether a cow survived another year of life given that the cow calved as a 2-yr-old) ${ }^{\mathrm{a}}$

\begin{tabular}{lllllll}
\hline \hline Trait & ST1 & ST2 & ST3 & ST4 & ST5 & ST6 \\
\hline ST1 & & 0.65 & 0.48 & 0.19 & 0.09 & 0.13 \\
ST2 & 0.68 & & 0.82 & 0.55 & 0.26 & 0.19 \\
ST3 & 0.49 & 0.82 & & 0.73 & 0.40 & 0.36 \\
ST4 & 0.19 & 0.54 & 0.73 & & 0.73 & 0.62 \\
ST5 & 0.11 & 0.29 & 0.43 & 0.75 & & 0.78 \\
ST6 & 0.11 & 0.18 & 0.35 & 0.62 & 0.78 & \\
\hline
\end{tabular}

${ }^{\mathrm{a} C}$ Correlations among ETA with the threshold model above diagonal; correlations among ETA with the linear model below diagonal.

were somewhat greater between adjacent measures of stayability for both stayability to calving and stayability to weaning.

Correlations among ETA for ST5, SC5, and SW5 with linear and threshold models are summarized in Table 16. Estimates of correlations between ETA within trait with threshold and linear models were 0.99 between ST5T (stayability to $5 \mathrm{yr}$ after first calving with a threshold model) and ST5L (stayability to $5 \mathrm{yr}$ after first calving with a linear model), 1.00 between SC5T (stayability to 5 th calving given the cow had birthed a calf with threshold model) and SC5L (stayability to 5th calving given the cow had birthed a calf with linear model), and 1.00 between SW5T (stayability to 5th weaning given the cow had weaned one calf with threshold model) and SW5L (stayability to 5th weaning given the cow had weaned one calf with the linear model). These correlations of near unity suggest ranking would be expected to be similar or the same among sires with both linear and threshold models. Estimates of correlations among ETA across traits were moderate between both measures of stayability to different ages (ST5L and ST5T) with both measures of stayability to calving (SC5L and SC5T) and with both measures of stayability to weaning (SW5L and SW5T), ranging from 0.57 to 0.51 , suggesting possibly important reranking of sires depending of the age criteria chosen. Large estimates of correlations $(0.86)$ were found between both conditional measures of stayability to calving (SC5L and SC5T)

Table 14. Correlations among estimated transmitting abilities of sires for stayability to calving (e.g., SC2 is a measure of whether a cow had two calves given that the cow had a calf as a 2-yr-old) ${ }^{a}$

\begin{tabular}{llllll}
\hline \hline Trait & SC2 & SC3 & SC4 & SC5 & SC6 \\
\hline SC2 & & 0.83 & 0.78 & 0.68 & 0.70 \\
SC3 & 0.84 & & 0.90 & 0.79 & 0.76 \\
SC4 & 0.79 & 0.90 & & 0.85 & 0.79 \\
SC5 & 0.69 & 0.80 & 0.86 & & 0.86 \\
SC6 & 0.68 & 0.75 & 0.79 & 0.87 & \\
\hline
\end{tabular}

${ }^{\text {a}}$ Correlations among ETA with the threshold model above diagonal; correlations among ETA with the linear model below diagonal.
Table 15. Correlations among estimated transmitting abilities of sires for measures of stayability to weaning (e.g., SW2 is of measure whether a cow weaned two calves given that the cow weaned a calf as a 2 -yr-old) ${ }^{\mathrm{a}}$

\begin{tabular}{lccccc}
\hline \hline Trait & SW2 & SW3 & SW4 & SW5 & SW6 \\
\hline SW2 & & 0.81 & 0.76 & 0.67 & 0.68 \\
SW3 & 0.81 & & 0.87 & 0.75 & 0.71 \\
SW4 & 0.76 & 0.87 & & 0.86 & 0.83 \\
SW5 & 0.67 & 0.75 & 0.86 & & 0.84 \\
SW6 & 0.68 & 0.71 & 0.83 & 0.84 & \\
\hline
\end{tabular}

${ }^{\mathrm{a} C o r r e l a t i o n s ~ a m o n g ~ E T A ~ w i t h ~ t h r e s h o l d ~ m o d e l ~ a b o v e ~ d i a g o n a l ; ~}$ correlations among ETA with linear model below diagonal.

with both measures of stayability to weaning (SW5L and SW5T), which show that stayability to calving and to weaning are genetically similar measures of stayability.

\section{Implications}

Selection for stayability is possible and could be effective. Selection for stayability to calving or weaning is more accurate than selection for stayability to a specific age, due to higher estimates of heritability compared to stayability to a specific age; however, prolongation of the generation interval would be expected with any direct measure of stayability. Selection for weights at weaning or yearling ages has had little effect on genetic change for any measure of stayability. Similar rankings of sires were found with threshold and linear models. Large estimates of correlations among estimated transmitting abilities for stayability at calving and weaning suggest that stayability at early ages may provide good predictors of stayability to later ages. Similar estimates of heritability and genetic and environmental trends, as well as large estimates of correlations among estimated transmitting abilities, were found using both the linear and threshold models; thus, the easier-to-implement linear model may be sufficiently effective.

Table 16. Correlations among estimated transmitting abilities of sires for ST5, SC5, and SW5 with threshold and linear models ${ }^{\mathrm{a}}$

\begin{tabular}{lccccc}
\hline \hline Trait & ST5T & ST5L & SC5T & SC5L & SW5T \\
\hline ST5L & 0.99 & & & & \\
SC5T & 0.55 & 0.56 & & & \\
SC5L & 0.55 & 0.57 & 1.00 & & \\
SW5T & 0.52 & 0.53 & 0.86 & 0.86 & \\
SW5L & 0.51 & 0.52 & 0.86 & 0.86 & 1.00 \\
\hline
\end{tabular}

${ }^{\text {aST5T }}$ and ST5L = measure of stayability to $5 \mathrm{yr}$ after first calving given that the cow calved as a $2 \mathrm{yr}$ old with threshold and linear models, respectively. SC5T and SC5L = measure of stayability to 5th calving given the cow had a calf once as a $2 \mathrm{yr}$ old with threshold and linear models, respectively. SW5T and SW5L = measure of stayability to 5 th weaning given the cow had weaned a calf as a 2 yr old with threshold and linear models, respectively. 


\section{Literature Cited}

Bijma, P., and J. Jensen. 1996. Genetic analysis of herd life and stayability in Danish dairy cattle. Pages 156-160 in Proc. Int. Workshop on Genet. Improv. Functional Traits in Cattle, Gembloux, Belgium. Interbull, Uppsala, Sweden.

Blair, H. T., and E. J. Pollak. 1984. Estimation of genetic trend in a selected population with and without the use of a control population. J. Anim. Sci. 58:878-886.

Breslow, N. E., and D. G. Clayton. 1993. Approximate inference in generalized linear mixed models. J. Am. Stat. Assoc. 88:9-25.

DeLorenzo, M. A., and R. W. Everett. 1986. Prediction of sire effects for probability of survival to fixed ages with a logistic linear model. J. Dairy. Sci. 69:501-509.

Doyle, S. P., B. L. Golden, R. D. Green, and J. S. Brinks. 2000. Additive genetic parameter estimates for heifer pregnancy and subsequent reproduction in Angus females. J. Anim. Sci. 78:2091-2098.

Greer, R. C., R. W. Whitman, and R. R. Woodward. 1980. Estimation of probability of beef cows being culled and calculation of expected herd life. J. Anim. Sci. 51:10-19.

Hudson, G. F. S., and L. D. Van Vleck, 1981. Relationship between production and stayability in Holstein cattle. J. Dairy Sci. 64:2246-2250.

Kachman, S. D. 2001. Analysis of generalized linear mixed models with MATVEC. Available: http://statistics.unl.edu/faculty/steve/ glmm/glmm_ithaca.pdf. Accessed Sept. 2, 2004.
Koch, R. M., L. V. Cundiff, and K. E. Gregory. 1974a. Selection in beef cattle. I. Selection applied and generation interval. J. Anim. Sci. 39:449-458.

Koch, R. M., L. V. Cundiff, and K. E. Gregory. 1974b. Selection in beef cattle. II. Selection response. J. Anim. Sci. 39:459-470.

Koch, R. M., L. V. Cundiff, and K. E. Gregory. 1994. Cumulative selection and genetic change for weaning and yearling weight plus muscle score in Hereford cattle. J. Anim. Sci. 72:864-885.

Robertson, A., and I. M. Lerner. 1949. The heritability of all or none traits: Viability of poultry. Genetics 34:395-411.

Searle, S. R., G. Casella, and C. E. McCulloch. 1992. Variance Components. John Wiley \& Sons, Inc., New York, NY.

Snelling, W. M., B. L. Golden, and R. M. Bourdon. 1995. Within-herd analyses of stayability of beef females. J. Anim. Sci. 73:993-1001.

Van Doormaal, B. J., L. R. Schaeffer, and B. W. Kennedy. 1985. Estimation of genetic parameters for stayability in Canadian Holsteins. J. Dairy Sci. 68:1763-1769.

Vega, V. E. 1999. Herd life, stayability and lifetime production in beef cattle. Ph.D. Diss., Univ. of Nebraska, Lincoln.

Vollema, A. R., and A. F. Groen. 1996. Genetic parameters of longevity traits of an upgrading population of dairy cattle. J. Dairy Sci. 79:2261-2267.

Wang, T., R. L. Fernando, and S. D. Kachman. 2002. Matvec User's Guide. Version 1.03. Available: http://statistics.unl.edu/faculty/ steve/software/matvec/. Accessed July 15, 2002. 